\title{
A Vaccine Against Ignorance?
}

\author{
J. T. Trevors • M. H. Saier Jr
}

Published online: 23 February 2011

(C) The Author(s) 2011. This article is published with open access at Springerlink.com

One of the greatest challenges facing humanity is ignorance - the lack of reliable information about and knowledge of the natural world we live in. Those who have studied the workings of the universe realize that the physical laws that govern our planet are the same as those that govern activities throughout the universe. This generalization certainly applies to the laws of physics, chemistry, and thermodynamics that we have learned after much scientific effort. Thus, life as we know it on Earth may follow the same dictates as life throughout the Universe, with some expected variations dependent on conditions. The discovery of life on other planets and in other galaxies would greatly expand our world view. It would allow us to more easily relate to each other and to other living organisms here and elsewhere, so that the common themes and the magnificence of life's diversity could be better appreciated.

There are so many ways in which we can seek knowledge, both about the natural world and about the unnatural world, designed by humans. These

J. T. Trevors $(\square)$

School of Environmental Sciences, University of Guelph, Guelph, ON N1G 2W1, Canada

e-ma:1 jtrevors@uoguelph.ca

M. H. Saier $\operatorname{Jr}(\bowtie)$

Division of Biological Sciences, University of California, San Diego,

La Jolla, CA 92093-0116, USA

e-mail:msaier@ucsd.edu human-designed systems include our financial and economic systems-whether they be capitalistic, socialistic, or communistic, for example. Some societies may be more prone to one of these options than others. Thus, the capitalistic systems of economy follow the one principal rule: the rule of profit making. All else must bow down to this rule. For this reason, a capitalistic system cannot be expected to provide for its citizens without strictly imposed regulations on the capitalistic system itself; the owners of industry yield to their specific selfish interests - usually short term - without thoughts about the greater good of humankind or long-term planetary sustainability. The current USA is an example of a failed capitalistic state in which essential long-term goals such as prevention of climate change and limitation of human population growth are subjugated to the short-term profit motive and the principle of economic growth. It seems incredible that the richest nation on Earth is the only developed country not to have signed the Kyoto Accord and to be unwilling to provide health care for its citizenry.

So why has the USA failed so miserably to act in the interests of the common good? The answer lies at the human root of capitalism. The existence of human-caused Global Warming is an established fact with no evidence to contradict the basis for its occurrence. And the theoretical basis was established over 50 years ago! So why are so many people in the USA so confused? To answer this question, we can go back to the days when the harmful effects of cigarette 
smoking were still being debated. The debate continued for a couple of decades, long after the scientific data were unequivocal, because lies continued to be propagated about the harmful effects of cigarette smoking on human health. The result? Legislation to protect American citizens was delayed for over 10 years. Next, the institute turned to aerosols, claiming that the scientific evidence for a connection with the depletion of stratospheric ozone was inadequate or simply wrong. They continued these arguments even after the Nobel Prize had been awarded for the theory and experimental demonstration of the tight connection we all recognize today. There are undoubtedly still some Americans today who question the scientific evidence regarding the causes of stratospheric ozone destruction.

Now, some people and special interests continue to propagate misleading information about climate change. They are using all of their newly gained knowledge (on how to fool the public) to enhance their greedy benefits. Once the method of scientific inquiry is understood, and the knowledge of how to evaluate scientific claims is at hand, people are not likely to be swayed or confused by misinformation. Some poorly educated people, on the other hand, will be at the whim of the profiteers, not being able to distinguish a lie from a statement based on scientific data. In fact, the more complex an explanation, the more distasteful it might appear to them. These people do not want to be burdened with factual information that their backgrounds do not prepare them to conceptualize; they want to believe in ideas that require minimal intellectual effort. They are likely to prefer a fairy tale to reality; it's so much nicer (for a while) to think that no serious problems exist. Such people just continue to live in a fantasy world that will dissolve when reality becomes oppressive, just as does a dream fades away after one wakes. Then it will unfortunately be too late to correct the problems that were propagated by ignorance.

Some governments tend to value and maintain the status quo. But our world is always changing, and to keep up, we must change with it. This requires governmental change, providing clear information to a confused citizenry. It requires financial assistance for our educational systems at all levels. But there is far more need: a deep feeling of compassion and responsibility towards all, a feeling of dedication to the welfare of humans and other beings on the planet. We believe these values can also be cultivated through education.
They certainly will not result from the yielding to the greedy interests of profiteers! Unless the impediments that prevent people from gaining the educations they desire are overcome, we will remain intellectual barbarians. Moreover, we need principles in order to live responsible and caring lives. Even sympathy and empathy can be learned. One's life's experiences should be our primary teachers, but many, blinded by their greed, do not learn. How can they be taught? Can they be injected with a vaccine that will cause them to see the light? Is there a vaccine against ignorance? If so, that vaccine must be education. Education, perhaps, in human rights and needs, sociology, psychology, jurisprudence, and logic. Would it work? We suspect that will depend on the individual: Some will continue to pursue their own selfish interests at the expense of others; only the more secure may be able to see beyond the horizon of greed.

Many countries devote inordinate amounts of money and other resources to the military and propaganda. Major fractions of federal budgets are spent on military, on immigration control, on spying, on deception, and on clandestine unethical behavior. As a result, wealthy countries cannot provide sustenance, birth control, housing, and medical care for its citizens. The urge of the insecure is to spend excessively on military, even when the military approach has proven futile as in Iraq and Afghanistan. Just imagine how much good the wealthy countries could do if they would focus on constructive measures rather than on weapons of destruction. A mere $\$ 30$ billion per year would provide all countries in the world with the means to limit their populations, so that citizens everywhere would have a chance to live decent, productive lives. As long as the human population does not increase, but instead goes into decline-without compulsion-it seems likely that with intuition and intelligence, the human population might be able to solve its grave problems.

Humanity certainly needs to be immunized with a vaccine for ignorance, and we propose that that vaccine is education. But education would have to be coupled to restrictions on people, agencies, and corporations determined to follow the profit motive, and in so doing, undermine the intelligence of the populace. Just imagine the outcome: ignorance would fade into the background, and discrimination, racism, intolerance, terrorism, crime, and fraud would be countered by the larger more rational segments of the human population. We 
might find that there could be unification of countries within organizations like the United Nations. And nonprofit organizations that try to help rather than harm others would receive much more support. If this could be achieved, we might be able to combat human population growth, global pollution, and the other disastrous human activities that plague us. Perhaps then, humanity could move forward.

We are not suggesting the resurrection of a utopian wish. This is a call for the citizens of the world to combat ignorance so humanity can move forward to achieve sustainability. Clearly, we must succeed in controlling human population growth so we can manage global pollution, that immense driver of global climate change. However, this goal can only be achieved when the inferior ideas and thoughts in ignorant human minds are eliminated from the equation and replaced with superior ideas resulting from a sound education. And with this education will follow a genuine concern for humanity. Humanity can then proceed forward, reducing human population growth and preventing to spread of life-threatening pollution into the only biosphere we have.

But education is expensive, difficult, and time consuming. And it requires effort-lots of it. We will have to overcome the irrational pull of mysticism and mythology. We will have to shift our emphasis away from destruction and towards mutual benefit. We will have to submerge our selfish desires for the betterment of humanity and the planet. We will have to change our way of thinking. Can we do so? Let's hope so, for the sake of all humanity and the biosphere. We simply need to do much better.

Open Access This article is distributed under the terms of the Creative Commons Attribution Noncommercial License which permits any noncommercial use, distribution, and reproduction in any medium, provided the original author(s) and source are credited. 